\title{
Effect of Aging Treatment on Fatigue Behaviour in Extruded AZ61 and AZ80 Magnesium Alloys
}

\author{
Yoshihiko Uematsu, a ${ }^{1,}$ Keiro Tokaji, ${ }^{1, b}$ and Masahiro Matsumoto ${ }^{2}$ \\ ${ }^{1}$ Gifu University, 1-1 Yanagido, Gifu 501-1193, Japan \\ ${ }^{2}$ Hayashi Telempu Co. Ltd., 1-4-5 Kamimaezu, Naka-ku, Nagoya 460-0013, Japan \\ ayuematsu@gifu-u.ac.jp, ${ }^{b}$ tokaji@gifu-u.ac.jp
}

Keywords: Fatigue, Magnesium alloy, Aging treatment, Microstructure, Crack initiation

\begin{abstract}
The effect of aging treatment on fatigue behaviour in extruded Mg alloys AZ61 and AZ80 was studied. Rotary bending fatigue tests were performed using as-received and aged specimens. Two different aging conditions, $\mathrm{T} 6$ and $\mathrm{T} 5$, were evaluated. $\mathrm{Mg}_{17} \mathrm{Al}_{12}$ precipitated near grain boundaries and within grains by aging treatments. In both materials, the T6-treated specimens showed significantly lower fatigue strength than the as-received specimens, which was more remarkable in AZ80, while the T5-treated specimens exhibited slightly higher fatigue strength in AZ80. It was indicated that the effect of aging treatment on fatigue strength was mainly attributed to the change in fatigue crack initiation mechanism.
\end{abstract}

\section{Introduction}

Magnesium (Mg) alloys have excellent properties such as light weight, high specific strength and stiffness, machinability and recyclability. They are increasingly used in the transportation industries, in particular, as components in aeroplanes or ground vehicles for which weight saving is extremely important. Wrought $\mathrm{Mg}$ alloys generally have superior mechanical properties to cast ones, thus they are suitable for load-bearing components. However, the absolute strengths of $\mathrm{Mg}$ alloys are lower than those of their competitors, such as aluminium (Al) alloys. Therefore, it is necessary to improve the mechanical properties of wrought $\mathrm{Mg}$ alloys. The $\mathrm{AZ}$ series $\mathrm{Mg}$ alloys are common structural alloys whose main chemical compositions are $\mathrm{Mg}, \mathrm{Al}$ and $\mathrm{Zn}$. It is well known that $\mathrm{AZ}$ series alloys could be age-hardened and the aging behaviour has been widely studied in cast Mg alloy [1-7]. However, there have been limited studies on aging behaviour in wrought $\mathrm{Mg}$ alloys, particularly the effect of aging treatment on fatigue behaviour has not been studied.

In the present study, extruded AZ61 and AZ80 were aged under two different conditions with and without solution treatment before aging. Rotary bending fatigue tests have been performed using these alloys and the effect of aging treatment on fatigue behaviour was discussed.

\section{Experimental Details}

Materials. The materials used are AZ61 and AZ80 alloys whose chemical compositions (wt.\%) are listed in Table 1. Figures 1 (a) and (b) show the microstructures on the cross section perpendicular to the extrusion direction in the as-received condition. The average grain sizes are $13.2 \mu \mathrm{m}$ and $13.1 \mu \mathrm{m}$ in AZ61 and AZ80, respectively. In both materials, small precipitates are recognized along grain boundaries.

Heat Treatment. The solution treatment was performed at $410^{\circ} \mathrm{C}$ for $24 \mathrm{~h}$ followed by quenching into water. The microstructures of the solution treated materials are shown in Figs.1 (c) and (d). It can be seen that small precipitates observed in the as-received condition were redissolved into the matrix. In this study, two different aging treatments were investigated. The aging at $170^{\circ} \mathrm{C}$ was performed using the as-received and solution-treated materials, i.e. T5 and T6 treatments, respectively. T6 treatment was applied to both AZ61 and AZ80, while T5 treatment was only to AZ80. Hereafter, the 
Table 1 Chemical compositions of materials (wt.\%).

\begin{tabular}{ccccccccc}
\hline & $\mathrm{Al}$ & $\mathrm{Zn}$ & $\mathrm{Mn}$ & $\mathrm{Si}$ & $\mathrm{Cu}$ & $\mathrm{Fe}$ & $\mathrm{Ni}$ & $\mathrm{Mg}$ \\
\hline $\mathrm{AZ61}$ & 6.76 & 0.74 & 0.22 & 0.043 & 0.004 & 0.002 & $<0.001$ & Bal. \\
AZ80 & 8.4 & 0.6 & 0.3 & 0.03 & 0.003 & 0.003 & $<0.001$ & Bal. \\
\hline
\end{tabular}
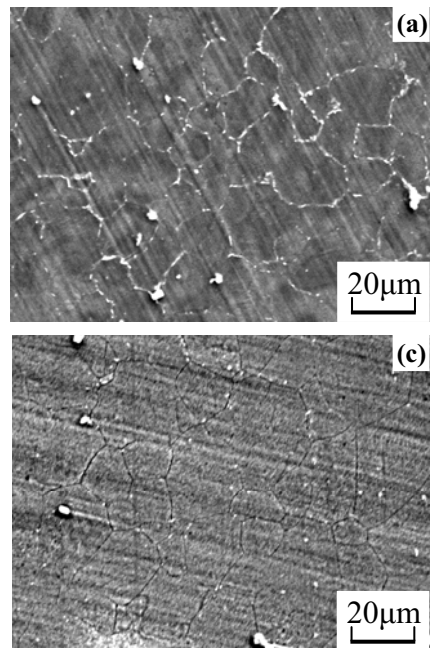
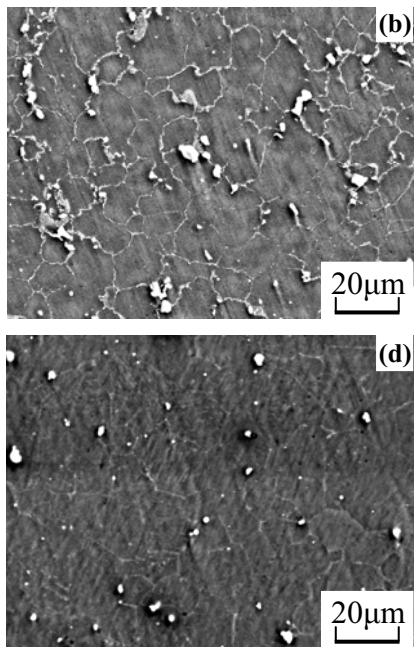

Fig. 1 Microstructures: (a) as-received AZ61, (b) as-received AZ80, (c) solution treated AZ61, (d) solution treated AZ80.

heat-treated materials are denoted such as AZ61-T6 and AZ80-T5.

Procedures. Smooth fatigue specimens with a diameter of $8 \mathrm{~mm}$ and a gauge length of $10 \mathrm{~mm}$ were machined from the as-received and heat-treated materials. Before fatigue test, they were mechanically polished using progressively finer grades of emery paper and buff-finished. Fatigue tests were performed using a $98 \mathrm{Nm}$ capacity rotary bending fatigue testing machine operating at a frequency of $50 \mathrm{~Hz}$ in laboratory air at ambient temperature. Hardness was measured by means of a micro-Vickers hardness tester at a load of $4.9 \mathrm{~N}(500 \mathrm{gf})$. The elementary analysis was performed by energy dispersive X-ray spectrometer (EDX).

\section{Results}

Aging Behaviour. Figure 2 shows Vickers hardness as a function of aging time. Both materials exhibit age-hardening where hardness reaches a peak value at about $15 \mathrm{~h}$ and $45 \mathrm{~h}$ in T6 and T5 conditions, respectively. These times were employed as aging times for both aging conditions. It should be noted that T5 treatment can achieve higher hardness than T6 treatment.

The microstructures of the aged specimens are revealed in Fig.3. Precipitates can be seen at grain boundaries and within grains by aging treatments. Precipitation occurs more remarkably in AZ80-T6 (Fig.3(b)) than in AZ61-T6 (Fig.3(a)), indicating that aging is promoted with increasing Al content. It should be noted that precipitation takes place more remarkable in T5 condition than in $\mathrm{T} 6$ condition (Figs.3 (b) and (c)). Figures 4 (a) and (b) show the magnified views of precipitates in AZ80-T6 and AZ80-T5, respectively. Lamellar-like precipitates are recognized within grains and form colonies in AZ80-T6 while uniformly distribute in AZ80-T5. Based on EDX analysis, these precipitates were defined as $\mathrm{Mg}_{17} \mathrm{Al}_{12}$ in which $\mathrm{Al}$ atoms were slightly substituted by $\mathrm{Zn}$ ones [3]. 


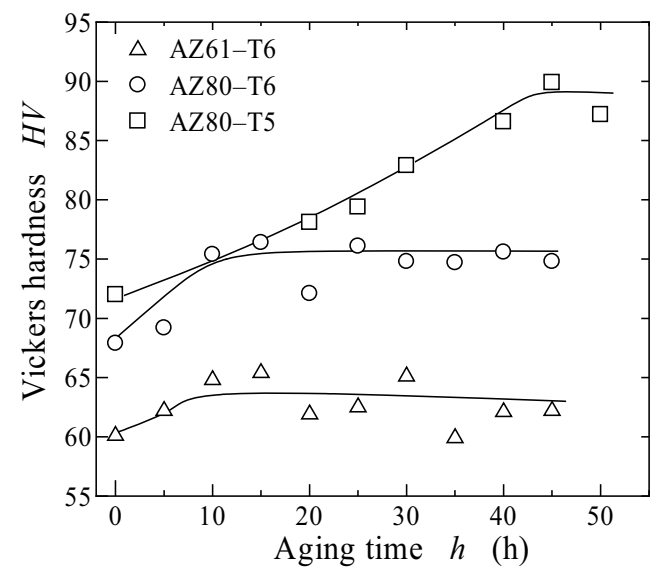

Fig. 2 Vickers hardness as a function of aging time at $170^{\circ} \mathrm{C}$.
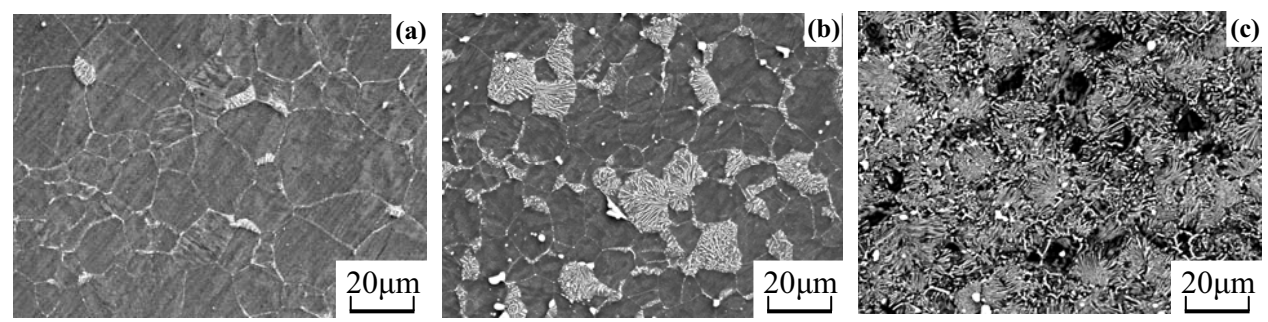

Fig. 3 Microstructures of aged materials: (a) AZ61-T6, (b) AZ80-T6, (c) AZ80-T5.
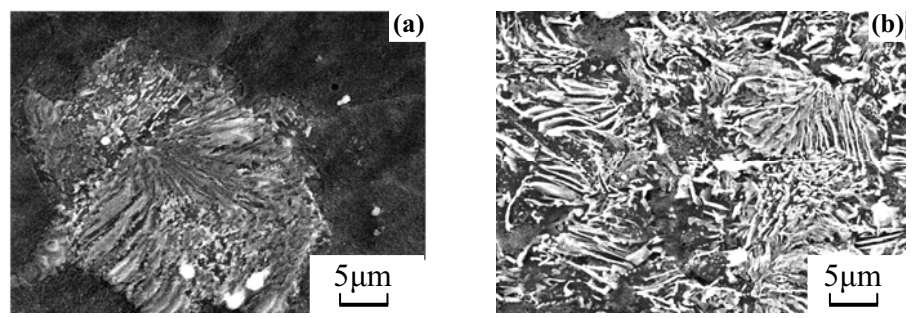

Fig. 4 SEM micrographs showing precipitates: (a) AZ80-T6, (b) AZ80-T5.

Mechanical Properties. The mechanical properties of the as-received and aged specimens are shown in Table 2. The effect of aging is not seen in AZ61 whose Al content is low. In AZ80, however, aging treatment can improve the mechanical properties, where the tensile strength in T5 condition is considerably higher than that in T6 condition. As can be seen in Fig.3, there is a large difference in the area fraction of precipitates between T6 and T5 conditions, thus it is believed that higher density of precipitates may result in the higher tensile strength.

Fatigue Behaviour.

Fatigue Strengths. Figures 5 (a) and (b) represent the $S-N$ diagrams for AZ61 and AZ80, respectively. In the as-received condition, AZ80 shows higher fatigue strength than AZ61 because of higher Al content. In AZ61, the T6-treated specimens exhibit lower fatigue strength than the as-received specimens. Similar result can also be seen in AZ80, but the decrease of fatigue strength is more pronounced compared with AZ61. On the contrary, fatigue strength is slightly increased by T5 
Table 2 Mechanical properties of materials.

\begin{tabular}{ccccc}
\hline & $\begin{array}{c}0.2 \% \text { proof } \\
\text { stress } \sigma_{0.2}(\mathrm{MPa})\end{array}$ & $\begin{array}{c}\text { Tensile strength } \\
\sigma_{\mathrm{B}}(\mathrm{MPa})\end{array}$ & $\begin{array}{c}\text { Elongation } \\
\delta(\%)\end{array}$ & $\begin{array}{c}\text { Elastic modulus } \\
E(\mathrm{GPa})\end{array}$ \\
\hline AZ61 & 206 & 297 & 13 & 38 \\
AZ61-T6 & 204 & 294 & 15 & 37 \\
\hline AZ80 & 244 & 329 & 13 & 39 \\
AZ80-T6 & 271 & 364 & 10 & 39 \\
AZ80-T5 & 278 & 393 & 12 & 39 \\
\hline
\end{tabular}
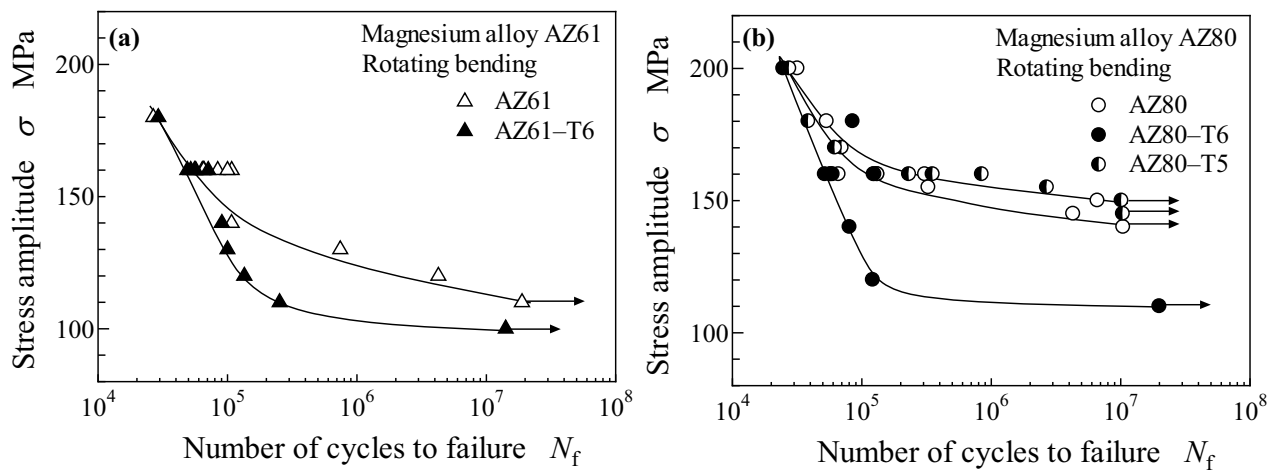

Fig. $5 S$ - $N$ diagrams: (a) AZ61, (b) AZ80.
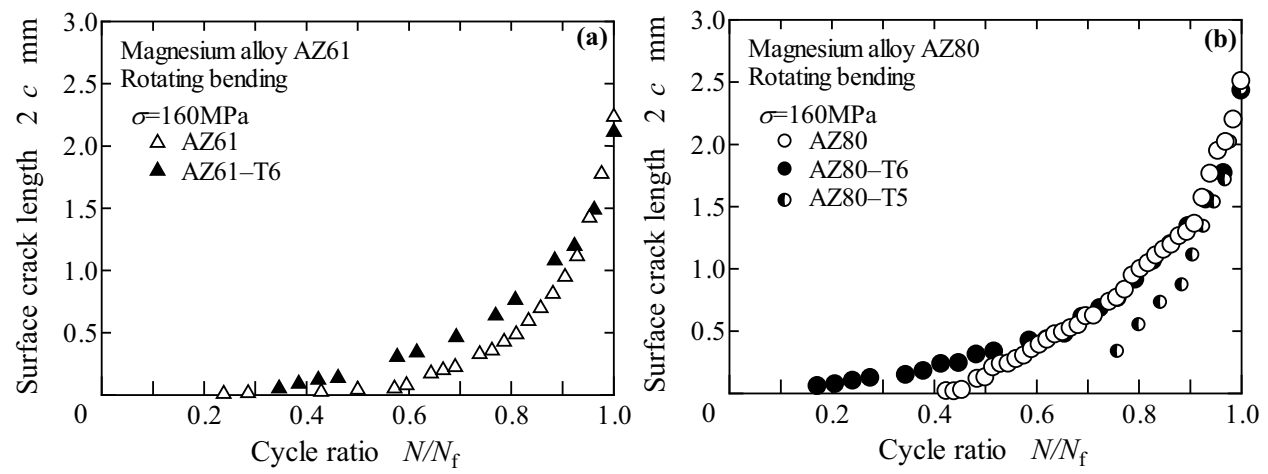

Fig. 6 Relationship between surface crack length and cycle ratio: (a) AZ61, (b) AZ80.

treatment compared with the as-received specimens.

Crack Initiation. The relationships between surface crack length, $2 c$, and cycle ratio, $N / N_{\mathrm{f}}$, for AZ61 and AZ80 are represented in Figs. 6 (a) and (b), respectively. In AZ61, crack initiation occurs nearly the same between the as-received and T6-treated specimens. In AZ80, however, crack initiation is significantly affected by aging treatment. Cracks initiated at approximately $15 \%, 40 \%$ and $70 \%$ of the total fatigue life in the T6-treated, as-received and T5-treated specimens, respectively, indicating that the crack initiation resistance is reduced by $\mathrm{T} 6$ treatment, while significantly enhanced by $\mathrm{T} 5$ treatment, compared with the as-received condition.

The crack initiation sites in AZ61 and AZ61-T6 are shown in Figs.7 (a) and (b), respectively. In both specimens, inclusions with the size of about $20 \mu \mathrm{m}$ can be seen at the crack initiation site. Cracks 

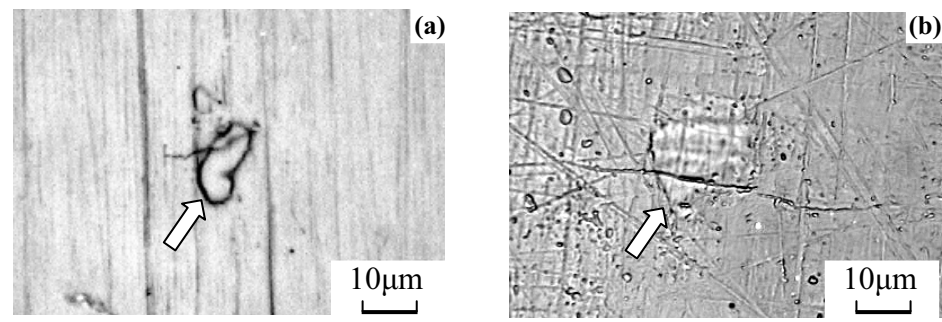

Fig. 7 Crack initiation at inclusions in AZ61: (a) AZ61, (b) AZ61-T6.
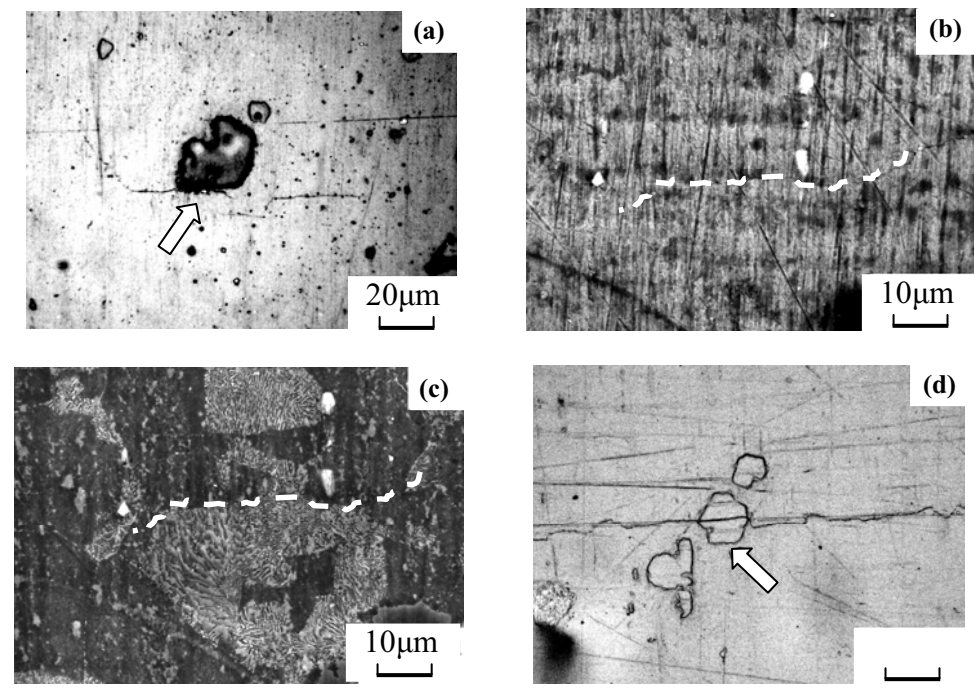

Fig. 8 Crack initiation sites in AZ80: (a) AZ80, (b) and (c) AZ80-T6, (d) AZ80-T5.

initiated at the boundary of the inclusions or due to the split of the inclusions. These inclusions were identified through EDX analysis as Al-Mn-based intermetallic compound. Such crack initiation at Al-Mn-based intermetallic compound has been reported in AZ series $\mathrm{Mg}$ alloys [8-10]. Figure 8 shows the crack initiation sites in AZ80. In the as-received specimen (Fig.8 (a)), crack initiated at the boundary of the inclusion that was also identified as Al-Mn-based intermetallic compound by means of EDX analysis. Figures 8 (b) and (c) are the crack initiation sites in T6 condition observed before and after etching, respectively, where the crack is indicated by the dotted line. It is evident that the crack initiated at the boundary of the colony of lamellar-like precipitates (Fig.8 (c)). In T5 condition (Fig.8 (d)), the crack initiated due to the split of the inclusion. From the observation of the crack initiation site of all fractured specimens, the crack initiation mechanisms are summarized in Table 3. It is noteworthy that the crack initiation mechanism is changed by aging treatment in AZ80 whose fatigue strength was affected by aging treatment, while not changed in AZ61, in which the effect of aging treatment was minimal.

Small Crack Growth Behaviour. Figures 9 (a) and (b) represent the relationship between crack growth rate, $\mathrm{d} a / \mathrm{d} N$, and maximum stress intensity factor, $K_{\max }$, in AZ61 and AZ80, respectively. The crack growth rates of AZ80 are slightly slower than those of AZ61 in the as-received condition. In AZ61, crack growth rates are nearly the same between the as-received and T6-treated specimens. In AZ80, crack growth rates become faster in the order of AZ80, AZ80-T6 and AZ80-T5, indicating that both aging treatments are detrimental to the small crack growth resistance. 
Table 3 Crack initiation mechanisms.

\begin{tabular}{ccc}
\hline Materials & Heat treatment & \multicolumn{1}{c}{ Crack initiation site } \\
\hline AZ61 & As-received & $\begin{array}{c}\text { Boundary between inclusion and matrix } \\
\text { or split of inclusion }\end{array}$ \\
\hline T6 & As-received & $\begin{array}{l}\text { Boundary between inclusion and matrix } \\
\text { Boundary between colony of } \\
\text { lamellar-like precipitates and matrix } \\
\text { Split of inclusion }\end{array}$ \\
\hline
\end{tabular}
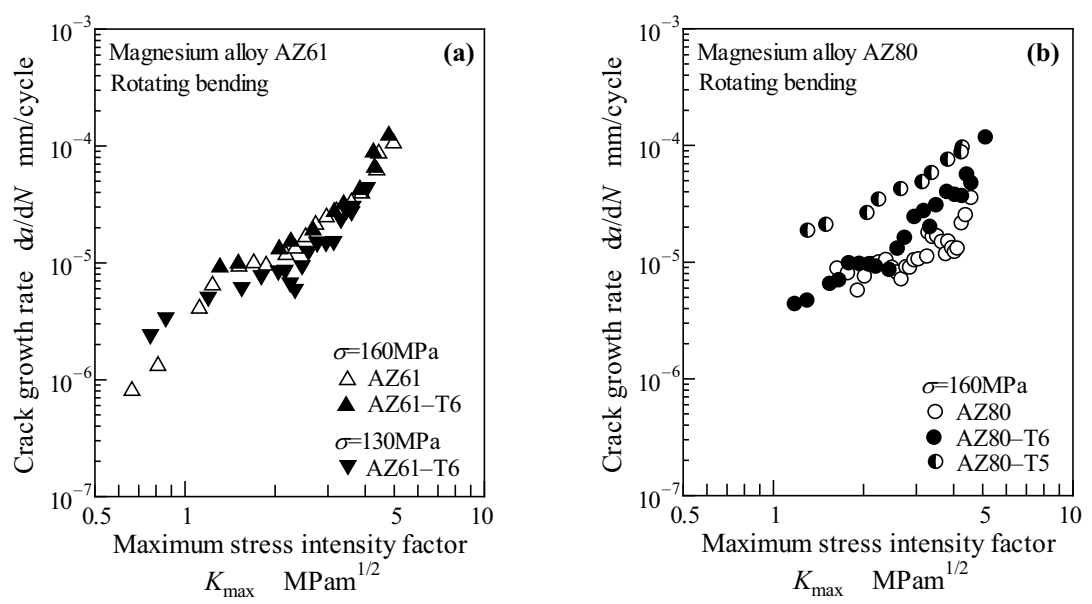

Fig. 9 Relationship between crack growth rate and maximum stress intensity factor:

(a) AZ61, (b) AZ80.

\section{Discussion}

Aging Behaviour. As shown in Figs.3 (a) and (b), the microstructure change due to T6-treatment was more pronounced in AZ80 than in AZ61. This suggests that Al content played an important role in aging behaviour because precipitates, $\mathrm{Mg}_{17} \mathrm{Al}_{12}$, are $\mathrm{Al}$ rich phase. Furthermore, in AZ80, precipitation occurred more remarkably in T5 condition than in T6 condition (Figs.3 (b) and (c)). It is believed that dislocations that acted as the precipitation nuclei disappeared by solution treatment before aging.

In AZ80-T6, Vickers hardness was measured within the colonies of lamellar-like precipitates and the matrix separately at a load of $0.49 \mathrm{~N}(50 \mathrm{gf})$. The obtained hardness was 99 in the colonies and 72 in the matrix. The hardness within the colonies, i.e. precipitates is much higher than that in the matrix, indicating that precipitates with higher hardness contributed to higher tensile strength of the aged specimens. The hardness of the as-received specimen measured at the same load of $0.49 \mathrm{~N}$ was 78 , which is slightly higher than the hardness in the matrix in T6 condition. The lower hardness of the matrix would be attributed to both lower dislocation density resulting from solution treatment and lower $\mathrm{Al}$ concentration in the matrix due to the precipitation of $\mathrm{Al}$ rich phase.

Crack Initiation. As summarized in Table 3, the crack initiation mechanism did not change by T6 treatment in AZ61. It is considered that the lower Al content of AZ61 resulted in the small effect of aging on the crack initiation resistance. In AZ80, on the contrary, the crack initiation mechanism changed due to aging conditions. The microstructure of T6-treated specimen consisted of hard 

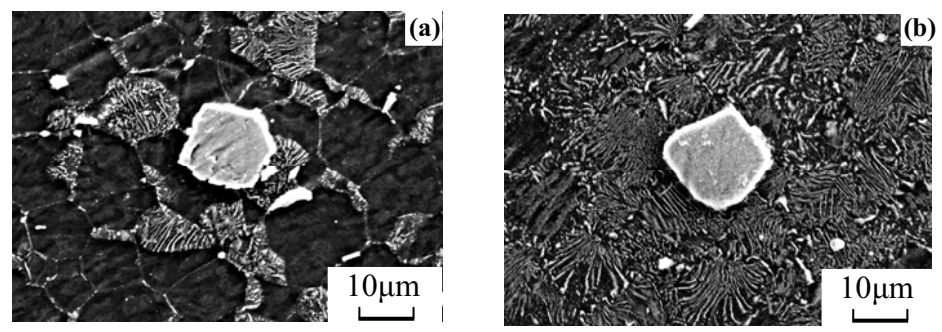

Fig. 10 Precipitates around inclusion in AZ80: (a) AZ80-T6, (b) AZ80-T5.
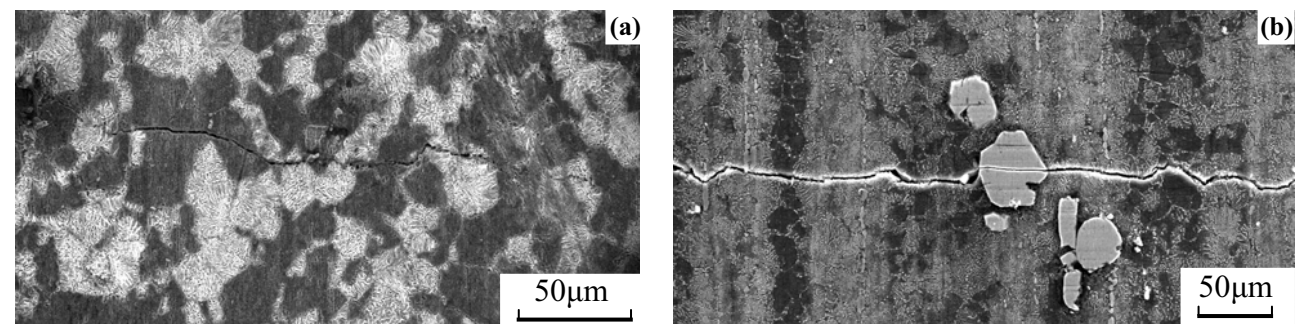

Fig. 11 Small crack growth path in AZ80: (a) AZ80-T6, (b) AZ80-T5.

colonies of lamellar-like precipitates and soft matrix, which induces the stress concentration around the colonies. It is known that the precipitates in the colonies are $\mathrm{Mg}_{17} \mathrm{Al}_{12}$ with bec structure and the lattice constant of $1.056 \mathrm{~nm}[2,3,7]$. Therefore, the volume of precipitates is larger than the matrix with hcp structure. Furthermore, $\mathrm{Mg}_{17} \mathrm{Al}_{12}$ precipitates grow along the basal plane (0001) of the magnesium alloy $[2,7]$, which is the preferred slip plane. Hence, the mismatch of hardness and volume on the preferred slip plane would result in lower crack initiation resistance at the boundary between the colony and the matrix in T6 condition. In T5 condition, however, the matrix is covered almost entirely with precipitates. Figures 10 (a) and (b) show the precipitates around the inclusion in T6 and T5 conditions in AZ80, respectively. It is believed that the uniformly distributed precipitates around the inclusion in T5 condition (Fig. 10(b)) would result in higher interface strength between inclusion and the matrix. Consequently, the change in crack initiation mechanism occurred in T5 condition, which led to the higher crack initiation resistance.

Small Crack Growth. In AZ61, the effect of aging on crack growth was very small similar to that on crack initiation because of the lower Al content. Small fatigue crack growth paths of AZ80-T6 and AZ80-T5 are shown in Figs.11 (a) and (b), respectively. In T6-treated specimen, the crack grew through the matrix and colonies of lamellar-like precipitates. It is assumed that the crack growth resistance of hard colonies is low because the crack grew directly into the colony without any deflection near the boundary whose interface strength was poor due to the mismatch previously described. Furthermore, the dislocation density and concentration of $\mathrm{Al}$ in the matrix are lower than the as-received specimen. Accordingly, low crack growth resistance of colonies and matrix resulted in faster crack growth rates in the T6-treated specimen than the as-received specimen. In T5-treated specimen, crack grew through the precipitates and the crack growth path is rather straight than that of T6-treated specimen, which results from the crack growth in brittle manner. This brittle crack growth, i.e. significantly lower plasticity and roughness-induced crack closure level are responsible for the observed fastest crack growth rates.

Effect of Aging on Fatigue Strength. In AZ61, the mechanical properties were not affected by T6-treatment, but the fatigue strength decreased compared with the as-received condition. This indicates that although the effect of aging is minimal due to the low Al content, T6 treatment is slightly detrimental to fatigue strength. On the contrary, the fatigue strength of AZ80 was strongly affected by aging treatments. In T6 condition, the crack initiation resistance was extremely lowered 
due to the change in crack initiation mechanism, leading to much lower fatigue strength. In T5 condition, the crack initiation resistance was improved, while the crack growth resistance was considerably lowered due to brittle crack growth and lower crack opening level. However, it is believed that the enhanced crack initiation resistance resulted in slightly higher fatigue strength than the as-received condition. It should be noted that aging treatment is beneficial to hardness and tensile strength, while fatigue strength depends on aging condition and one should select the aging condition by which the matrix is covered almost entirely with precipitates.

\section{Conclusion}

Rotating bending fatigue tests were performed using as-received and aged AZ61 and AZ80. Fatigue strength was evaluated and the effect of aging treatment on fatigue fracture mechanisms was discussed based on experimental observation. The following conclusions can be made.

1. $\mathrm{Mg}_{17} \mathrm{Al}_{12}$ precipitated by aging treatments, with more pronounced in AZ80 whose Al content was higher. The precipitation and age hardening occurred more remarkably in T5 condition than in T6 condition.

2. In AZ61, the mechanical properties was not affected by aging treatment, while in AZ80, they were significantly improved. The higher tensile strength was achieved by T5-treatment than by T6-treatment.

3. In both materials, fatigue strength was lowered by T6-treatment, particularly in AZ80, while slightly improved by T5-treatment, compared with the as-received condition.

4. In AZ61, there was no significant influence of T6-treatment on the crack initiation behaviour, while in AZ80, the crack initiation mechanisms changed due to aging conditions. In AZ80, fatigue cracks initiated at the boundary of inclusions, at the colony of lamellar-like precipitates and due to the split of inclusion in the as-received, T6 and T5 treated specimens, respectively.

5. In AZ61, the crack initiation resistance was not affected by T6-treatment, while in AZ80, it was enhanced by T5-treatment, but lowered by T6-treatment, compared with the as-received condition.

6. In AZ61, the crack growth behaviour was the same between the as-received and T6-treated specimens. In AZ80, the crack growth resistance was lowered by aging treatments, particularly by T5-treatment, indicating that aging treatments were detrimental to crack growth.

\section{References}

[1] A.F. Crawley and K.S. Milliken: Acta Metallurgica Vol. 22 (1974), p. 557

[2] S. Celotto: Acta Materialia Vol. 48 (2000), p. 1775

[3] S. Celotto and T.J. Bastow: Acta Materialia Vol. 49 (2001), p. 41

[4] M. Ohno, D. MicroVAX and R. Schmid-Fetzer: Acta Materialia Vol. 54 (2006), p. 3883

[5] A. Sinivasan, U.T.S. Pillai and B.C. Pai: Mater. Sci. Eng. A Vol. $452-453$ (2007), p. 87

[6] Y. Tamura, Y. Kida, H. Tamehiro, N. Kono, H. Soda and A. McLean: J. Mater. Sci. Vol. 43 (2008), p. 1249

[7] M.Y. Zheng, K. Wu, S. Kamado and Y. Kojima: Mater. Sci. Eng. A Vol. 348 (2003), p. 67

[8] Y. Uematsu, K. Tokaji, M. Kamakura, K. Uchida, H. Shibata and N. Bekku: Mater. Sci. Eng. A Vol. 437 (2006), p. 131

[9] Y. Uematsu, K. Tokaji and T. Ohashi: Strength of Materials Vol. 40 (2008), pp.141

[10] Z.B. Sajuri, Y. Miyashita, Y. Hosokai and Y.Mutoh: Int. J. Mech. Sci. Vol. 48 (2006), p. 198 